\section{Commentary: Injecting hope without making false promises}

\author{
Linda W. Martin, MD, MPH, FACS
}

Discussing prognosis is challenging, and for many of us, uncomfortable. Surgeons are fixers by nature and want to believe our surgical intervention will cure patients $100 \%$ of the time. In addition, many surgeons believe that cancer prognosis discussions are the job of oncologists. I disagree. As thoracic surgeons, we are frequently the first consultant for a patient with a lung mass, and unfortunately the positron emission tomography scan done along the way into the office for that first visit sometimes shows metastatic disease. It is our duty to initiate biopsy, complete staging, orchestrate referrals - this means we have to be equipped to explain the findings and ramifications, including prognosis. For early-stage thoracic cancers, we are the only specialist involved and patients rightfully want to know their chances, so yes, it is our job to have these conversations.

We are taught to first do no harm. But as Matthews ${ }^{1}$ so poignantly points out, honesty in discussing cancer prognosis and outcomes can be harmful, demoralizing, exacerbate depression, and worsen the quality of what may be a short remaining life span. On the other hand, unrealistic optimism adversely affects patient decision making about aggressiveness of care and will direct patients toward heroic measures when symptom management may be more appropriate. This feels ethically wrong; furthermore, it can contribute to excessive end-of-life spending on unnecessary or ineffective services. ${ }^{2}$ Finding that balance is not easy. How should we relay statistics to patients in a way that makes sense, is honest, and doesn't completely deplete patients of hope?

The 3 most common approaches to prognosis discussions are realism, optimism, and avoidance (eg, my crystal ball is broken). ${ }^{3,4}$ Trying to find that perfect balance of realistic hopefulness, peaceful awareness is the ultimate goal. One approach is to focus on concrete examples, using numbers

From the Department of Surgery and Cardiothoracic Residency Program, University of Virginia Health System, Charlottesville, Va.

Disclosure: Author has nothing to disclose with regard to commercial support.

Received for publication Feb 22, 2020; accepted for publication Feb 23, 2020; available ahead of print March 12, 2020.

Address for reprints: Linda W. Martin, MD, MPH, FACS, Department of Surgery and Cardiothoracic Residency Program, University of Virginia Health System, PO Box 800679, Charlottesville, VA 22908-0679 (E-mail: Lm6yb@virginia.edu).

J Thorac Cardiovasc Surg 2020;160:878

$0022-5223 / \$ 36.00$

Copyright (c) 2020 by The American Association for Thoracic Surgery

https://doi.org/10.1016/j.jtcvs.2020.02.113

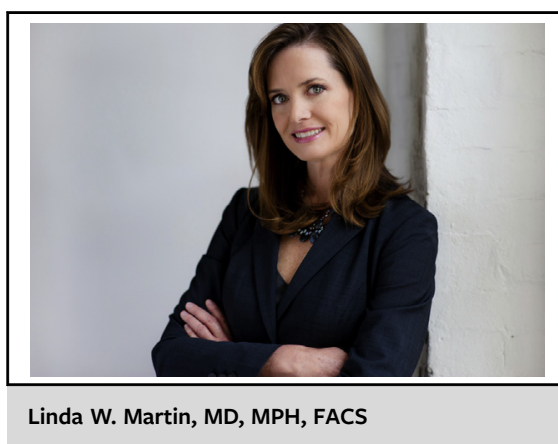

CENTRAL MESSAGE

It is part of our job as thoracic surgeons to discuss prognosis with our patients. We must strive for the delicate balance of realistic hopefulness and be thoughtful about how we deliver difficult information.

not percentages: Instead of saying 5-year survival is $50 \%$, a better explanation may be, "If 10 patients had the same diagnosis as you, 5 years from now, 5 of them would still be alive." Another strategy is to lay out best, worst, and most likely scenarios ${ }^{5}$; this is a way to digest the statistics, and give a more realistic interpretation of numbers to patients.

Regardless of what kind of concrete numbers we state to a patient, we should never forget to give hope along the way as well. Even patients with stage 4 disease can get curative treatment with the advent of new therapies such as immunotherapy, which has opened doors previously sealed shut. Finally, the job of a good thoracic surgeon is never finished. By simply asserting that you will be there for your patients whenever they need you, you are a light in the darkest of tunnels.

\section{References}

1. Matthews C. Thirty-three, zero, nine. J Thorac Cardiovasc Surg. 2020;160:871-5.

2. Emanuel EJ, Emanuel LL. The economics of dying. The illusion of cost savings at the end of life. N Engl J Med. 1994;330:540-4.

3. Levin TT. Discussing cancer prognosis. Oncology (Williston Park). 2015;29: 142-4. C143.

4. Lamont EB, Christakis NA. Prognostic disclosure to patients with cancer near the end of life. Ann Intern Med. 2001;134:1096-105.

5. Kiely BE, Tattersall MH, Stockler MR. Certain death in uncertain time: informing hope by quantifying a best case scenario. J Clin Oncol. 2010;28:2802-24. 